Hermans: Translation and Normativity

\title{
TRANSLATION AND NORMATIVITY
}

\section{Theo Hermans}

So much has been written in the last twenty years about norms and their relevance to translation that it is reasonable to assume at least a certain familiarity with the concept of norms as such (cf. Baker 1998 for a concise statement and references). Allow me therefore to preface my remarks with no more than a brief reminder, in the form of a quotation from Thomas Merton's 1942 essay 'The Normative Structure of Science'. It is a very traditional statement in more ways than one, but Merton's definition of 'the ethos of science' in terms of values and norms can readily be translated from the world of the sciences into that of translation:

The ethos of science is that affectively toned complex of values and norms which is held to be binding on the man of science. The norms are expressed in the form of prescriptions, proscriptions, preferences, and permissions. They are legitimized in terms of institutional values. These imperatives, transmitted by precept and example and reenforced by sanctions, are in varying degrees internalized by the scientist, thus fashioning his scientific conscience or, if one prefers the latter-day phrase, his superego. Although the ethos of science has not been codified, it can be inferred from the moral consensus of scientists as expressed in use and wont, in countless writings on the scientific spirit and in moral indignation directed toward contraventions of the ethos. (Merton 1973: 268-69)

With respect to translation, the expression of norms in the form of prescriptions, proscriptions, preferences and permissions, their legitimation in terms of institutional values, their transmission through precept and example, their re-enforcement by means of sanctions, and their overall regulative function, have all been extensively debated and documented, both in general terms and with reference to a number of individual cases. There is not much point in going over this familiar ground. Rather than rehearse the basic ideas and review the work done so far, I should therefore like to do two things. First, I want to suggest the productive potential of the norms concept as an analytical tool in the historical study of translation, highlighting one or two aspects that have perhaps not received the attention they deserve. After this methodological section I will go on to consider some theoretical and meta-theoretical implications of the norms concept and their relevance to the way we think and speak about translation.

I will start by looking at one historical example, to see what illumination, if any, there is to be had from a norms-based approach to it. I want to suggest that even when we are dealing with a single translation, an approach via the concept of norms can be fruitful in generating questions about and directing attention to certain aspects of the case. My focus will be on the translator's choices against a background of a limited range of practically available alternatives, and on the possible reasons why a particular option was selected from among that range. The privileging of selectivity has two distinct advantages. On the one hand, the choices which the translator makes simultaneously highlight the exclusions, the paths that were open but that were not chosen. On the other, the approach sheds light on the interplay between the translator's responses to existing expectations, constraints and pressures, and his or her intentional, goaldirected action. 
Hermans: Translation and Normativity

\section{De Buck's Boethius}

The case I want to present is of no great historical moment at all. Indeed it suits the purposes of illustration precisely because it is so utterly unremarkable, with the exception perhaps of one or two intriguing features that I intend to milk for all they are worth.

It concerns a seventeenth-century Flemish Catholic priest, one Adrianus de Buck, an obscure and now forgotten figure. Biographical details are almost entirely lacking. We know of only two publications by him: a book of prayers, and his translation, in 1653, of Boethius' Consolation of Philosophy, rendered from Latin into Dutch. The translation (of which there are only two extant copies) appeared in Bruges, i.e. in the Southern Netherlands then still under Catholic Spanish rule. Around the mid-sixteenth century the whole of the Low Countries had been ruled by the Spanish Habsburgs. In the 1560s an armed rebellion had broken out which at one point engulfed the entire area. The southern part - roughly, contemporary Belgium eventually returned to the Catholic fold and to Spanish rule. The Calvinist-dominated Northern Netherlands had emerged as a de facto independent republic in the 1590s. In the course of the first half of the seventeenth century the north became astonishingly prosperous and powerful, witnessing the explosion of creative talent that produced the likes of Rembrandt and Vermeer. Spain formally recognized the Dutch Republic as a sovereign state in 1648.

De Buck's translation of Boethius contains a dedication to a number of local dignitaries, a number of other liminary texts including the usual approbations and laudatory poems, and the main text in prose and verse. In his dedication (reprinted in Hermans 1996: 121-3) the translator leaves us in no doubt that he is green with envy at the miracle of Dutch culture in the Northern Netherlands, not least because, he says, they have appropriated the learning of every other language in the world, including Greek, Hebrew, Turkish and Arabic. In other words, De Buck was acutely aware of living in what, by comparison with the thriving republic in the North, was rapidly becoming a cultural backwater. Politically too the area was weak and vulnerable. The military threat however came not from the north but from the south, from France. Indeed the Southern Netherlands were experiencing the effects of France's expansionism. The small town of Veurne, where De Buck was living, is near the French border. It had been overrun a few years earlier by the armies of Louis XIV and Cardinal Mazarin, and was still occupied. Negotiations for a peaceful settlement had started but were not getting anywhere.

And so De Buck has now translated Boethius. He has done so, he tells us in the dedication, for several reasons: partly to offer consolation to his compatriots who have suffered at the hands of the French, partly because he reckons that the Protestant heretics in the North have left Boethius untranslated on account of the references to free will and to purgatory in the Consolation, and partly also because he wants to prove that, as he puts it, 'the sun also shines on our West-Flemish land and there is fire in our souls too' (...dat oock het West-Vlaender-landt van de Sonne beschenen wordt, ende dat'er oock vlamme woont in onse zielen). I will interpret these statements below. The translation itself follows the prose and verse in Boethius' Latin with corresponding prose and verse. The verse translations exhibit one curious feature: De Buck has rendered several of the poems in Boethius not once but twice, in two different metres.

Since a norms-based approach to translation starts from the assumption that the translation process involves decision-making on the part of the translator, it will focus on the question of what choices are made in relation to available alternatives, and what it is that steers translators towards one preferred option rather than another. I take it for granted that when we speak of norms we include the entire range from strict rules down to conventions (or 'quasinorms', as Poltermann 1992:17 calls them), the latter without a binding character backed up by 
sanctions (for a formal definition of 'convention', see Lewis 1969). In addition, I prefer to think of norms not only as regularities in behaviour and a certain degree of pressure exercised on the individual to prefer one option rather than another, but also as sets of expectations about preferred options, and as the anticipation of such expectations, i.e. as the expectation of expectations. Finally I like to think that the teleological aspect of translator behaviour comes into its own as translators consciously or unconsciously negotiate their way through and around existing norm complexes with a view to securing some form of benefit, whether personal or collective, material or symbolic.

In discussing De Buck's Boethius, I will look first at the selection of the source text, and then at De Buck's mode of translating. In this latter respect I will consider both De Buck's own comments on how he has translated some parts of his source text and at his actual practice. My argument will be, roughly, that De Buck is catering for three overlapping but not necessarily identical constituencies. He is writing, firstly, for his compatriots as political subjects, as fellow sufferers at the hands of the French, emphasizing the consolation to be had from reading Boethius. Secondly, he addresses them as co-religionists and self-conscious Catholics, dramatically claiming Boethius for the Counter-Reformation. Thirdly, he speaks to them as cultural agents, a culturally aware audience who may well be concerned, as he is, about the cultural dominance of the Northern Netherlands. Accordingly, in De Buck's Boethius we can trace different norms, political, religious and cultural, with different degrees of force, informing his decisions. At the same time we can read the way in which De Buck's negotiates the options in front of him as a strategy, a matter of goal-oriented calculation in order to achieve particular aims.

$1 \quad$ We can view De Buck's choice of Boethius as a source text in relation to the primary function of the translation. As De Buck explains in his preface, he wants to render a service to his compatriots as political subjects and fellow citizens. Although he does not tell us in so many words, we can safely interpret De Buck's decision to offer a translation in the first place, and not to write something of his own invention, against the background of the commonly held Renaissance view that to transmit the tried and tested sayings of some valued authority is often preferable to producing your own laborious and probably inept invention. For someone like De Buck, a provincial priest with (as far as I can tell) no long-term ambition to make his mark as a writer, the translating option must have seemed the obvious choice.

Why Boethius? Just as Boethius drew comfort from philosophical speculation at a time when he was in prison awaiting execution, so the hard-pressed citizens of Flanders will derive consolation from reading Boethius in their hour of need. That is what makes Boethius an apt choice for De Buck, in preference to an unspecified number of alternative possibilities. Just how many alternatives were realistically available to De Buck is obviously impossible to ascertain. The list will almost certainly have included works such as Justus Lipsius' De constantia of 1584 . Lipsius was a Catholic writer and enjoyed international fame as a Humanist at Louvain University, barely fifty miles from De Buck's town of Veurne. His De constantia, a dialogue in the Stoic tradition, had been written, like Boethius' Consolation, to find equanimity amid a sea of troubles and proved an immediate European bestseller. However, the book was readily accessible to De Buck's compatriots in a popular Dutch translation, with editions in 1584, 1621 and 1640 (Hoven 1997). In other words, highlighting obvious but excluded alternatives allows us to appreciate the significance of De Buck's selection, as we can see him making his own choice optimally relevant in view of what is already available in terms of suitable source texts. In providing solace and a morale-booster his translation constitutes an answer to a perceived problem. To emphasize the point his preface develops several apposite metaphors related to 
wounds and healing, and to loss of material goods as being outweighed by the retention of spiritual values.

Two other aspects of De Buck's choice of Boethius gain relief when we pick up his comments on the cultural and translational practices in the Northern Netherlands. De Buck notes that Boethius is not selected for translation there, and that this is for religious reasons: the references to free will are unacceptable to Calvinist doctrine. ${ }^{1}$ His awareness of this ideological aspect makes his own choice deliberate, but also oppositional, differential, polemical. His Boethius contributes to the differentiation of the Southern translational tradition vis à vis the Northern one, and this will have further ideological, political and religious repercussions as regards expectations about translated as well as other texts. Boethius, in this particular translation, emphatically Catholic and with some translational peculiarities like the 'double' rendering of some of the poems, is now becoming part of the Southern cultural landscape. Since the number of practically available options for placing Boethius in a religious and philosophical context is limited (Boethius as a universal Christian? As a moral philosopher? As a NeoPlatonist? As a Protestant thinker despite appearances?), De Buck's pointed appropriation of Boethius as Catholic also brings out these exclusions. Moreover, the ease with which Boethius could be claimed as a Catholic writer may well have made him preferable as a source to, say, Seneca or another Stoic.

In addition to identifying religion as a significant point of difference between a Protestant North and a Catholic South, De Buck's choice of Boethius also contributes to the ongoing refashioning of the Southern cultural tradition as a whole. It constitutes one small move in the deployment of translation, as of other cultural resources, in support of the militant CounterReformation. The strict criteria for text production prevalent in the political and religious spheres in the Spanish Netherlands are imposed on - or, from De Buck's point of view, eagerly imported into - the cultural and translational domain, in this case in the form of criteria for source text selection. Boethius is emphatically presented as a Catholic writer. De Buck's selection is clearly governed by and in turn strengthens already strong normative constraints. The selection is both structured and structuring. The constraints themselves are ideological in nature and resemble those prevalent in Spain and the rest of Catholic Europe at the time rather than those of the more tolerant Dutch Republic. And as De Buck allies himself with Counter-Reformation Europe, he simultaneously opposes the Protestant North.

2 If a translation offers a verbal representation of an anterior text across a semiotic boundary, and typically a representation such that it can serve as a full-scale re-enactment of its source across an intelligibility barrier, then every translation constitutes a selection of a particular mode of representation from among a wider range of available, permissible modes. The set of permissible modes - the ensemble we also refer to as the 'constitutive' norms and conventions of translation - circumscribes the concept of translation in the world of which De Buck is a part. The selection which he makes will determine the words on the page, the translation's specific verbal orchestration or 'style'. As was the case with source text selection, the choice of a particular style or representational mode highlights the exclusions going with it,

1. Boethius' De consolatione philosophiae had been translated in the Northern Netherlands by the independently-minded D.V. Coornhert (1522-90), who saw himself as a universal Christian. Coornhert's translation appeared in Leiden in 1585 and was reprinted in Amsterdam in 1616 and 1630. A year after De Buck's 1653 translation Coornhert's version was reissued in revised form by François van Hoogstraten, an Erasmian with Catholic sympathies (Dordrecht 1654, 1655). De Buck's assessment is therefore broadly correct. 
and thus points up the existence of alternative possibilities, of paths not chosen, as well as of certain stylistic and representational allegiances, similar choices made by other writers and translators. In De Buck's Boethius some of these allegiances and exclusions are made explicit. They are thematized, or dramatized, both in the translator's preface and in the unusual decision to render some of the Latin poems twice, in two different forms.

In his preface De Buck informs us that he has translated the title of Boethius' book 'in an explanatory manner' (tot breeder verklaringh). Indeed, what in Latin reads as a book 'on the consolation of philosophy' (De consolatione philosophiae liber) has in Dutch been expanded into a 'comforting pharmacy of moral wisdom' (Troost-Medecijne-wynckel der zedighe wysheyt). The expansive rendering stresses the aspect of healing and the practical usefulness of moral philosophy. For De Buck this paraphrastic mode is clearly a legitimate form of translating, which suggests that the concept of 'translation' he is operating with is already internally differentiated, marked by various sets of 'regulatory' (as opposed to 'constitutive') norms and conventions. Apart from the standard mode of translating, which apparently does not require comment, there is also this other mode. The paraphrastic rendering of the title would here seem to be a matter of convention only, a personal preference within an area of relatively free variation. Since he wants to emphasize the soothing effect that comes from practical moral philosophy, he avails himself of an existing, permissible mode of translation to achieve that goal.

Equally paraphrastical (een luttel wijdt-loopigh, 'somewhat long-winded'), De Buck tells us, are the renderings of some of the verses which he confesses he sometimes found very hard to grasp in the Latin even after consulting learned commentaries, on account of the abstruse mixture of Aristotelian and Platonic ideas which they contain. The reason for the paraphrastic mode in this instance appears to lie in the elucidation of conceptual obscurity.

The fact however that in both these cases he feels the need explicitly to justify his recourse to a paraphrastic mode with reference to specific places and specific reasons suggests that, although it is a legitimate form of translating and hence one that meets existing expectations about what constitutes translation, i.e. one that stays within the perimeter policed by the constitutive norms and conventions of translation, De Buck recognizes it as more marginal than the standard mode of translating. This is presumably because paraphrase, requiring the translator to speak more overtly in his or her own name, tends to forms such as glossing, commentary, or imitation. These forms are all adjacent to, may occasionally overlap with but are definitely not coterminous with the prevailing concept of translation. In other words, through De Buck's comments the boundaries of translation as he and presumably a number of his contemporaries understand them, come clearly into view as well.

Then there are the 'double' translations, in two different metres, of some of the poems. This procedure is, without a doubt, unusual and unexpected. It is not entirely unknown at the time, but normally found in personal albums or commonplace books, and associated with shorter, highly crafted literary forms such as epigrams. The option to translate verse into verse is undoubtedly dictated by a norm, but since different verse forms are available to the translator (indeed Boethius employs different metres) the choice for a particular form appears to be a question of convention. De Buck does not tell us why he chose to translate some poems twice. It may be that we have to see his decision in light of his statements about paraphrastic translation. But then the question arises: why two verse forms? If conceptual elucidation by means of loose paraphrase was the aim, prose would have been a more obvious and equally available choice. To my mind - and this is pure speculation on my part - the 'double' renderings do not primarily serve the translation's function as representation. Rather, they do two things. Firstly, they dramatize the fact that there are alternative possibilities, demonstrating that choice in this instance is merely a 
matter of convention; secondly, and more importantly, they serve as displays of virtuosity to underscore a claim to professional equality vis à vis the translators in the North.

As for the first point, in providing an emphatic comment on free choice within the bounds of permissible translational modes, the dual renderings remind the reader that the translation's basic function, that of providing a serviceable representation of an otherwise inaccessible source text, allows in practice for more than one stylistic option, at least as far as the verse is concerned. Both poetic forms which De Buck is offering are presented as valid; both remain metrical, though. Since there is no suggestion that the two options which he has chosen exhaust the range of valid modes, his practice signals a degree of tolerance in the choice of poetic form to render poetic form. Subsequent translators may want to act on De Buck's precedent and take up either or both models that he has supplied. To the extent that future reader expectations are affected by De Buck's example, however, they will be cognitive rather than normative expectations, within a normatively circumscribed range of acceptable verse forms.

But De Buck's 'double' translation also supports a conspicuous bid for recognition and legitimacy by a Southern translator vis à vis what he evidently perceives as the more successful tradition in the North. By demonstrating virtuosity in verse translation the practitioner in the weaker system can claim professional equality with translators in the dominant system, while still distancing himself in religious and therefore in ideological terms. In this respect too De Buck may well be exploiting the opportunity offered by the absence of a strong normative constraint governing the choice of a particular verse form in verse translation.

In passing, and on a very different level, let me also note that the 'double' translation introduces a discursive complication into the text. From a standard communicative point of view the repetition is redundant; even if the reader finds it useful as a help to understanding complex theological and philosophical ideas, its occurrence clearly undermines the illusion that we are reading Boethius and registering only a single voice as we do so. The translator's presence in the text is unmistakable. In thus drawing attention to the translator's presence as a discursive subject, the Dutch text reveals its hybrid, plurivocal nature.

As far as the prose passages are concerned, here De Buck evidently had other priorities: providing solace, and vindicating Boethius as a Catholic author. That is why his vocabulary here borrows directly from the terminological and discursive resources of Catholic theology and liturgy. In so doing De Buck also helps to consolidate the hegemony of Catholic discourse in the vernaculars of Counter-Reformation Europe. But it is worth bearing in mind that what is alliance in one direction, that of Catholic, southern Europe, is self-assertion through deliberate competition and emphatic differentiation in another, i.e. that of the Protestant Dutch Republic.

In De Buck's case, of course, the alliance with the values of the Counter-Reformation Church is unsurprising. He was a Catholic priest. Lay translators in the Spanish Netherlands, however, in marked contrast with those in the more tolerant and decentralized North, would not have had appreciably more room for manoeuvre. In their case the ideological pressure might be less enthusiastically internalized and hence their behaviour more immediately inspired by the wish to avoid sanctions and censorship. The results would have been the same.

\section{Translation, Norms and Values}

There is more in De Buck's Boethius that merits attention, but let us leave the discussion of this particular translation and briefly review the gain that may be derived from a case like this. Several things could be singled out.

The first point is an obvious one. The example can serve to suggest the heuristic 
relevance of proceeding with a norms concept as a guiding tool. This does not mean using norms as causal explanations. It does mean exploring the whole range from conventions to norms to decrees, in different, intersecting spheres and on different, interconnected levels, to see how they bear on the decisions involved in the translation process. It also means weighing external pressures, acquired habits and routinely applied skills against the individual's presumed goaloriented design in particular circumstances. Determining what factor or aspect is most relevant in individual instances is likely to remain a matter of interpretation and speculation. It is, as always, the observer who constructs the case before him or her, rendering data relevant by deploying them as evidence.

Secondly, focussing on norms not primarily as regularities in behaviour extracted from large corpora but as a matter of prevailing normative as well as cognitive expectations and the selective aspect of the individual translator's choice for a particular option in the context of a limited range of realistically available alternatives, allows for the use of the concepts of norms and conventions as a way of asking questions not only about what is there on the page but also about what might have been there but, for one reason or another, is not. Trying to figure out what those reasons might be can prove illuminating. Assessing the exclusions lets us appreciate the significance to the inclusions.

But it is time to open up the perspective. It seems to me that there are currently several broader theoretical frameworks that could give added resonance to the norms concept as it has been used hitherto in the study of translation. Some of these already left echoes in my discussion of De Buck's Boethius. For example, my emphasis on De Buck's choices as meaningful selections in a differential context, i.e. as acquiring meaning through their selectivity and thus against the background of the more or less likely alternatives that were excluded, is indebted to the social systems theory of Niklas Luhmann, as does the stress on norms reinterpreted in terms of expectations. For Luhmann, social systems consist of communications which connect over time; normative as well as cognitive expectations about communications form the structure of a social system. However, I do not want to elaborate here on Luhmann's complex and quite abstract systems theory, as this would lead us too far afield. Suffice it to say that Luhmann's voluminous writings on social systems have been applied to areas ranging from ecology and education to art history. I can see no reason why they could not be applied to the world of translation. $^{2}$

The other name to be mentioned here is that of Pierre Bourdieu. For all the substantial differences between Luhmann and Bourdieu, both are sociologists who think primarily in relational terms, and both are alive to issues of language and culture. As far as translational norms are concerned, it is perfectly possible to view their acquisition by the individual translator in Bourdieu's terms as the inculcation of a durable, transposable disposition, i.e. a habitus which is both structured and structuring, forming a link between the individual and the social. In the same way the translator's manoeuvring within and between norm complexes prevalent in a particular field lends itself to description in terms of Bourdieu's concept of social positions and position-takings, the accumulation of symbolic or other capital and the struggle for the monopoly of defining 'translation' ?

2. As far as I am aware Poltermann 1992 was among the first to apply Luhmann's system concept to norms and translation. See also Hermans 1997.

3. Approaches to literature making use of the ideas of Luhmann and Bourdieu are discussed in the special issue 'The Study of Literature and Culture: Systems and Fields' of the Canadian Review of Comparative Literature (Van Gorp et al. 1997). Gouanvic 1997 and Simeoni (forth- 
Within the broadly descriptive and historicizing approach to translation, the elaboration of concepts derived from sociological theories like those of Luhmann or Bourdieu seems a promising and exciting prospect to me. The eminently 'social' notion of norms, assimilated into expectations or dispositions, offers an obvious point of departure. But there is also another dimension which the notion of translational norms opens up.

Social conventions, norms and rules are intimately tied up with values. The content of a norm is a notion of what a particular community regards as correct or proper. The directive force of a norm is there to secure and maintain these values. The assumption is roughly that norms serve as the active ingredient by means of which general values are transmuted into guidelines and prompters for concrete action. The dominant values, and hence the dominant norms, of communities tend to reflect the hierarchies of power in those communities.

If norms, understood in this sense, are relevant to acts of translation, then translation can never be value-free. The example of De Buck's Boethius will have made that clear. In claiming Boethius as a Catholic (and therefore emphatically not a Protestant or a universal Christian) writer, the translator shows his perception to be ideological, perspectival, slanted, overdetermined, manipulative. When De Buck then translates Boethius, the dislocation brought about is ideological as well as linguistic, temporal, geographical and communicative. And this is inevitable: we can only perceive and make sense of the world from our own point of view. Moreover, since translation invariably caters for other discourses, it has to reckon with the norms and values that prevail in the social domains sustained by those discourses. This means that the representations and re-enactments produced by translation cannot be transparent or ideologically neutral. Through the operation of norms they incorporate the values that gave rise to them in the first place.

On that basis I want to suggest three points. First, what makes translation interesting as a cultural phenomenon is precisely its lack of transparency, i.e. its opacity and complicity. Secondly, if translation always puts a slant on representation, then retaining the notion of equivalence in critical thinking about translation becomes problematical. And thirdly, if equivalence is discredited, what needs to be explained is why it has played and continues to play such a key part in the common perception and the self-presentation of translation.

\section{Translation as an Index of Self-Reference}

As for the first point, we know that translations appropriate, transform and relocate their source texts, adjusting them to new communicative situations and purposes. Just how much and what kind of attuning is prescribed, proscribed, preferred or permitted in practice, will depend on prevailing concepts of translation, including their normative aspects, and on who has the power to impose them.

The specific way in which a community construes translation therefore determines the way in which individual translations refer to their prototexts, the kind of image of the original which translations project. The 'anterior text' to which a translation refers is never simply the source text, even though that is the claim which translations commonly make. It is a particular image of it, as André Lefevere (1992) argued. And because the image is always slanted, coloured, pre-formed, never innocent, we can say that translation constructs or produces or, in Tejaswini Niranjana's words (1992: 81), 'invents' its original. A culture's value system, together with the norm complexes which serve to hold it in its place, see to it that translation is governed by at

coming) have applied Bourdieu's concepts to translation. 
Hermans: Translation and Normativity

least three normative levels: general cultural and ideological norms which may be held to apply throughout the larger part of a community; translational norms arising from general concepts of translatability and cross-lingual representation alive in that community; and the textual and other appropriateness norms which prevail in the particular client system for which individual translations cater.

If this is true, then the whole cognitive and normative apparatus which governs the selection, production and reception of translations, together with the way in which translation generally is circumscribed and regulated at a certain historical moment, presents us with a privileged index of cultural self-reference. In reflecting about itself, a cultural community defines its identity in terms of self and other, establishing the differential boundary in the process. Translation offers a window on cultural self-reference in that it involves not simply the importation of selected cultural goods from the outside world, or indeed their imposition on others, but at the same time, in the same breath as it were, their transformation on the basis of and into terms which are always loaded, never innocent. Translation is of interest precisely because it offers first-hand evidence of the prejudice of perception and of the pervasiveness of local concerns. If translations were neutral, transparent, unproblematic, they would be dull and uninformative, either in themselves or as documents of cultural history and the history of ideas. They would be about as interesting as xerox machines. But because they are opaque, complicit and compromised, the history of translation supplies us with a highly charged, revealing series of cultural constructions of otherness, and therefore of self. Being non-transparent, translations perhaps tell us more about those who translate than about the source text underlying the translation. It is the bias built into the practice of translation, the uses made of translation and the ways in which translation is conceptualized, that gives insight into how cultures perceive and place themselves.

In this perspective it is relevant to note that the very notion of translatability already contains an assumption of the commensurability of languages and cultures. Resistance or indifference to translation, or the absence of translation where it was an option, or indeed the claim to untranslatability, are as informative as the pursuit of this or that particular type of translation. And it is useful to bear in mind that when translation occurs it is always a particular, circumscribed and often institutionally transmitted type of translation. Translators do not 'just translate'. They translate in the context of certain conceptions of and expectations about translation, however much they may take them for granted or come to regard them as natural. Within this context translators make choices and take up positions because they have certain goals to reach, personal or collective interests to pursue, material and symbolic stakes to defend. That is where the concrete interplay of the personal and the collective takes place. As the norms concept constantly reminds us, translators, like those who use or commission translations, are social agents.

\section{Equivalence and Difference}

Let me go on to my second point, the issue of equivalence. One of the reasons why Gideon Toury's introduction of the norms concept into the study of translation has proved to be of such strategic importance was that it has directed attention away from the vexed notion of equivalence and focussed instead on the factors governing the choices that determined the relation between source and target texts. In Toury's words: 'norms [...] determine the (type and extent of) equivalence manifested by actual translations' (1995: 61). Equivalence has thus effectively been sidelined, and demoted. In the traditional approach equivalence was posited as both the aim and 
precondition of translation: every translation was thought to strive to attain equivalence, and only those renderings which achieved equivalence of the required kind to a sufficient degree could be qualified as translations. In Toury's empirical approach it is reduced to a mere label designating the outcome of an operation which for one reason or another has been taken to constitute translation. Since Toury is keen - and rightly so - to cover 'the possibility of accounting for every kind of behaviour which may be culturally regarded as translational' he employs the term equivalence to mean 'any relation which is found to have characterized translation under a specified set of circumstances' (1995: 61), or, more fully: equivalence is 'a functional-relational concept' standing for 'that set of relationships which will have been found to distinguish appropriate from inappropriate modes of translation performance for the culture in question' (1995: 86).

Having hollowed out the notion of equivalence to such an extent, Toury has decided nevertheless to hang on to it. Indeed he expresses 'a clear wish to retain the notion of equivalence', even though it has now been reduced to an 'historical' concept (1995: 61). And he repeats elsewhere that the study of individual translations will 'proceed from the assumption that equivalence does exist between an assumed translation and its assumed source', adding again that '[w] hat remains to be uncovered is only the way this postulate was actually realized' (1995: 86).

Now, when we consider the primary role of norms and values in the perception and cross-lingual refashioning of source texts, it seems to me that retaining the notion of equivalence as the outcome of translation and then simply moving on, has unfortunate consequences. First stripping equivalence down to a mere label and then re-introducing it by the back door without further questioning the term's implications, blurs precisely the aspect of non-equivalence, of manipulation, dislocation and displacement which the norms concept did so much to push into the foreground. This blurring of non-equivalence is unfortunate for two reasons.

First, it is the aspect of non-equivalence which constantly reminds us that the whole process of cultural contact and transmission of which translation forms part is governed by norms and values, and by what lies behind them: power, hierarchy, non-equality. As postcolonial approaches to cultural history have shown again and again, relations between communities and cultures are never relations between equals. The refusal of some contemporary Irish poets to have their work translated into English, an obvious instance of the political significance of nontranslation, occurs in a context in which languages like English and Irish are not on an equal footing. In the years following 1513 the so-called 'Requerimiento' which informed the American Indians of their place in the Spanish empire was read to them in Spanish only; any translations into local languages faced not just the linguistic and cultural displacement that translation brings with it, but at the same time their lack of legal validity. Around the turn of the nineteenth century the decrees issued by the revolutionary French regime in annexed territories like Belgium were in French only; while in the Flemish region translations into Dutch appeared alongside the French, only the French version possessed legal force. To speak of equivalence is such cases, with its suggestion of equal value, is like speaking of translation as exchange, or as bridge-building, suggesting fairness, friendship and two-way processes but obscuring translation's onedirectionality and its complicity in relations of power. Even if semantic equivalence is granted, that aspect cannot undo the simultaneous non-equivalence in other, equally relevant respects which pertain to the status and role, and therefore the sense and significance, of translations.

The second point is more paradoxical. Just as Luhmann has observed that what needs to be explained is the improbability of communication, given the many good reasons why it is unlikely to succeed, so it seems to me that what needs to be explained as regards translation is not what kind and extent of equivalence is manifested by translations, but why, in the face of glaring 
linguistic, cultural and other differences, concepts of translation have nonetheless emerged in which equivalence can still be posited, even taken for granted and given prominence. By retaining equivalence in our critical vocabulary, even in a watered-down version, we sidestep that issue, we make it impossible even to ask the question. The norms concept however should serve as a reminder that it is difference, not sameness or transparency or equality, which is inscribed in the operations of translation. Starting from difference as a prime condition, we need to account for the occurrence and durability of the unlikely notion of equivalence. One way of doing this, I suggest, is to consider equivalence as part of the cultural construction of translation.

We tend to think of translation in terms of relayed communication. The translator acts as a relay station: enabler, conduit and transformer at the same time. On this side of the language barrier we feel we can place our trust in the translator's mediating role because we assume that the transformation leaves the source message essentially intact. Although we realize that the original and the translation are not quite identical, we trust the translator's competence, integrity and good faith and hence assume that this integrity extends to the substitute message we are being offered: it must be a faithful reproduction, a reliable duplicate, a quality replica. The standard metaphors of translation incessantly rehearse these aspects in casting translation, on the one hand, as bridge-building, ferrying or carrying across, transmission, transfer, trans-latio, 'meta-phor', and, on the other, as resemblance, likeness, mimesis. A translation may be a derived product, a mere copy and therefore secondary, second-hand and second-best, but as long as there is nothing to jolt us out of our willing suspension of disbelief we assume that to all intents and purposes the replica is virtually 'as good as' and therefore equivalent with the real thing.

To the extent that translations manage to produce, or to project, a sense of equivalence, a sense of transparency and trustworthiness which entitles them to function as full-scale representations and hence as reliable substitutes for their source texts, statements like 'I have read Dostoevsky' pass as legitimate shorthand for saying 'I have actually read a translation of Dostoevsky', with the implication that this is practically as good as reading the original. But note: only to the extent that a 'sense' of equivalence, of equality in practical use value, has been produced. And we tend to believe that this 'sense' of equivalence results from the reliability of the translation as reproduction, as resemblance, as transparency. A translation, we say, is most successful when its being a translation does not get in the way, does not distract., does not detract from our presumption of integrity. A translation most coincides with its original when it is most transparent, when it approximates pure resemblance.

This requires that the translator's labour leave no identifiable trace of its own, that it be negated or sublimated. The irony is, of course, that those traces, those words, are all we have, they are all we have access to on this side of the language barrier. Yeltsin may well speak right 'through' an interpreter, but all we have to make sense of are the interpreter's words. Nevertheless we say that Yeltsin declared so-and-so, that we have read Dostoevsky. Even though it is precisely the authoritative originary voice that is absent, we casually declare it is the only one that presents itself to us.

We feel we can be casual about this because we construe translation as a form of delegated speech, a kind of speaking by proxy. This implies not only a consonance of voices, but also a hierarchical relationship between them, and a clear ethical - often even a legal - imperative, that of the translator's discretion and non-interference. The imperative has been formulated as the 'honest spokesperson' or the 'true interpreter' norm, which calls on the translator simply and accurately to re-state the original, the whole original and nothing but the original (Harris 1990). ${ }^{4}$

4. Speaking of interpreters, Harris posits the existence of a 'fundamental and universal' norm, which he calls 'the "true interpreter" norm, or ... the norm of the "honest spokesperson"'. He 
Hermans: Translation and Normativity

The model of translation here is direct quotation: the translator's words appear within quotation marks because they are someone else's words, which are presented to us with minimal mediation. Although the translator speaks, it is not the translator who speaks. Translators, like their products, become transparent, spirit themselves away in the interests of the original's integrity and authority. Only the translator who operates with self-effacing discretion can be trusted not to violate the original. Transparency guarantees integrity, consonance, equivalence.

Now, the norms concept is there to remind us, forcefully, that what I have been describing - in the form of a caricature, perhaps, but not by much - is an illusion, a supreme fiction. We all know that a translation cannot coincide with its source. It contains different words, different meanings. Not only the language changes with translation, so does the enunciation, the intent, the moment, the function, the context. The translator's intervention cannot be erased without erasing the translation itself. Translation is necessarily hybrid, overdetermined, opaque, different. The belief in equivalence is an illusion, a pragmatically and socially necessary illusion perhaps, but an illusion nevertheless. And whatever is taken to constitute equivalence at one level, however measured, is offset by non-equivalence at other levels. Which leaves us with having to explain a paradox: if translation cannot undo difference, why is it that the presumption of equivalence has become so deeply ingrained in our standard concepts of translation? The notion of a 'translator function' may provide an answer.

\section{The Translator Function}

In the last thirty years or so, literary theory has had repercussions throughout the humanities. Among many other things, it has emphasized the role of the reader in investing texts with meaning, and highlighted the role of convention and intertextuality in the production of texts that are themselves variations on existing texts. As a result, we have come to appreciate not only the inexhaustibility and irrepressibility of meaning, but also, at the same time, the various conventional and normative mechanisms by means of which we have attempted to control this proliferation of meaning.

In 'The Death of the Author' Roland Barthes proposed that a text should be seen not as the sovereign creation of some Author-God but as 'a tissue of quotations drawn from the innumerable centres of culture' (1977: 146). When readers interpret texts they set them against this backdrop of known words and phrases, existing statements, familiar conventions, anterior texts. The meaning of a text is what individual readers extract from it, not what a supreme Author put in. Barthes' essay concludes by declaring that 'the birth of the reader must be at the cost of the death of the Author' (1977: 148).

Michel Foucault's essay 'What is an Author?' continues this line of thought by enquiring into the historical construction of the concept of 'the author' and its role in relation to questions of knowledge and power. Claiming that the concept of the author is 'a certain functional principle by which, in our culture, one limits, excludes, and chooses; in short, by which one impedes the free circulation, the free manipulation, the free composition, decomposition, and recomposition of fiction' (1979: 159), he posits the concept of the 'author function' as the ideological figure that

goes on to explain that ' $\mathrm{t}$ ] his norm requires that people who speak on behalf of others, interpreters among them, re-express the original speakers' ideas and manner of expressing them as accurately as possible and without significant omissions, and not mix them up with their own ideas and expressions. Occasionally this norm is made explicit, as in the oaths which court interpreters have to swear under some jurisdictions' (1990: 118). 
our culture has devised to keep the potentially unbounded proliferation of meaning within bounds. We do this primarily by insisting on the author as a single unifying subject, with a single voice, behind the text. We thus suppress the more uncontrollable aspects of texts, their inflationary semantics, their explosive potential for interpretation, their plurality and heterogeneity.

Now, as especially Karin Littau $(1993,1996)$ has argued, translation constantly pushes in precisely the direction which the 'author function' was designed to block. Translations compound and intensify the refractory increase in voices, perspectives and meanings, they simultaneously displace and transform texts, and produce interpretations which, as verbal artefacts, are themselves open to interpretation even as they claim to speak for their originals. If, then, our culture needed an 'author function' to control the semantic potential and plurality of texts, it is not hard to see why it has also, emphatically, created what we might call a 'translator function' in an effort to contain the exponential increase in signification and plurivocality which translation brings about. $^{5}$

As an ideological and historical construct, the 'translator function' serves to keep translation in a safe place, locked in a hierarchical order, conceptualized and policed as derivative, delegated speech. The metaphors and oppositions by means of which we traditionally define translation, the expectations we bring to translated texts, the self-images that translators themselves hold up, the legal constraints under which translation nowadays operates, all accord with this function. Because we know translation is strictly, normatively controlled, we feel entitled, against our better judgement, to override its inherent difference and presume equivalence. And so we say we read Dostoevsky, or Boethius. Just as we commonly accept that the most reliable translation is an 'authorized' translation, the one formally approved and legally endorsed by the author. The term itself confirms the singularity of intent, the coincidence of voice, the illusion of equivalence and, of course, the unmistakable relation of power and authority. The translator may claim authorship of the target text's words, but we want the original author to authorize them.

Historically this hierarchical positioning of originals versus translations has been expressed in terms of a number of stereotyped oppositions such as those between creative versus derivative work, primary versus secondary, unique versus repeatable, art versus craft, authority versus obedience, freedom versus constraint, speaking in one's own name versus speaking for someone else. In each instance it is translation which is subordinated, circumscribed, contained, controlled. And in case we imagine that these are after all natural and necessary hierarchies, it will be useful to remember that our culture has often construed gender distinctions in terms of strikingly similar oppositions of creative versus reproductive, original versus derivative, active versus passive, dominant versus subservient. The point I want to make in this connection is not just that the historical discourse on translation is sexist in casting translation in the role of maidservant, faithful and obedient wife, or 'belle infidèle', or that it puts women in their place by confining them to silence or translation. It is that translation has been hedged in by means of hierarchies strongly reminiscent of those employed to maintain sexual power relations. It is worth asking whose interests are being served by these hierarchies.

It may well be, then, that the common perception of translation is that of an operation

5. Myriam Díaz-Diocaretz 1985 also speaks of a 'translator-function', but without explicitly basing her usage of the term on Foucault; see also Robinson 1997: 61-77. Rosemary Arrojo (1997: 31), too, has recently spoken of a 'translator function' with explicit reference to Foucault. 
which produces equivalence, whatever the actual textual outcome. But it is a perception which privileges equivalence at the cost of suppressing difference. The interesting thing about the norms concept, and the issue of value raised by it, is that it invites us not only to recognize the primacy of difference but also to seek to explain the tenacity of equivalence. Let me add, for clarity's sake, that I do not think it necessarily follows from these remarks that translators should opt for different ways of translating. To my mind, the critical task of translation theory does not consist in advocating this or that 'resistant' - or, for that matter, compliant or 'fluent' or whatever - mode of translation. It consists, rather, in theorizing the historical contingency of these modes together with the concepts and discourses which legitimize them. The primary task of the study of translation is not to seek to interfere directly with the practice of translation by laying down rules or norms, but to try to account for what happens on the ground, including the ways in which translation has been conceptualized. To the extent however that the historical discourse on translation blends into the contemporary scholarly discourse, our speaking about translation has to develop a self-reflexive and self-critical dimension. This takes me to my final point.

\section{Translating Translation}

There is one further, awkward complication to which I would like to draw attention. The essence of it was very neatly put by the historian Quentin Skinner in the essay 'Conventions and the Understanding of Speech Acts' (1970). Skinner is here addressing the problem of how to assess the 'illocutionary force' of statements made by someone in a different context and not intended for us. The problem, Skinner says, is relevant to historians and anthropologists, who 'overhear' utterances produced by other for others. We can represent it as involving a person A, at a time and/or place $\mathrm{t} 2$, who is trying to make sense of an utterance by a speaker $\mathrm{S}$ who was speaking at t1. As Skinner points out, the problem 'is neither philosophically trivial in itself, nor in the practice of these disciplines can it be readily overcome' (1970: 136). Of course, A has to know enough about the concepts and conventions available to $S$ at $t 1$ so that $A$ can grasp the semantics of S's utterance and what force S's enunciation of that utterance must have registered when it was uttered. But in addition, ' $\ldots$ it also seems indispensable that A should be capable of performing some act of translation of the concepts and conventions employed by $\mathrm{S}$ at $\mathrm{t} 1$ into terms which are familiar at $\mathrm{t} 2$ to A himself, not to mention others to whom A at $\mathrm{t} 2$ may wish to communicate his understanding' (ibid.; emphasis added, TH).

In other words, if we want to understand what Boethius intended to say when we moderns 'overhear' his De consolatione philosophiae, we have to know something about the conventions of Boethius' time and place to grasp both the meaning of his words and the force registered by his uttering those words in those circumstances. It is worth remembering that this 'knowing' on our part is already a construction, determined by our perception and our conceptual categories. In addition however - and this is the main point - we need to be able to translate Boethius' concepts and conventions into our modern terms, especially if we wish to talk or write about our understanding of Boethius. So what if the object of our attention is not Boethius but a translation of Boethius? If we want to understand De Buck's translation of Boethius and communicate about it, we not only need to have a sense of De Buck's concepts and of his practice of translation, we also need to be able to translate his concepts and practice of translation into our translational concepts. To understand and speak about someone else's translation, we must translate that translation. When we want to understand someone's discourse about translation, we have to translate that discourse and the concept of translation to which it refers. Our accounts of translation are themselves a form of translation. 
Two things follow from this. First, if descriptions of translation are performing the operations they are simultaneously trying to describe, the distinction between object-level and meta-level is rendered problematical. Descriptive translation studies in particular have been keen to keep object-level and meta-level well apart, but it turns out the object constantly contaminates its description (as indeed Bakker 1995 has argued from a Deconstructionist angle). Even the scholarly study of translation is implicated in the self-description of translation as a cultural construct. There is a worm in the bud of descriptive translation studies and their claim to disciplinary rigour.

Secondly - and here the norms aspect comes back into the picture - in translating other people's concepts of translation (or whatever term they use which we reckon we can translate as 'translation'), our accounts are unlikely to hold up a transparent image. They must be based on concepts of translation. As we saw, precisely because translation is norm-governed and impregnated with values, it is never diaphanous, never innocent or transparent or pure, never without its own intermingled voices. On the contrary, it appropriates, transforms, deflects and dislocates everything within its grasp. To the extent, then, that our descriptions amount to translations of practices and concepts of translation, they are subject to all the manipulations that come with translation. The nature and the direction of these manipulations are themselves socially conditioned and hence significant for what they tell us about the individuals and communities performing the translative operation, i.e. about ourselves. The study of translation continually rebounds on our own categories and assumptions, our own modes of conceptualizing and translating translation.

This is not new. Like other branches of the human sciences which cannot escape entanglement in the objects they describe, the discourse about translation, too, is obliged to render concepts and practices of 'translation' into its own terms. The issue becomes acute, however, as soon as we move beyond our immediate horizon. It surfaces whenever we wish to speak about 'translation' generally, as a transhistorical or transcultural phenomenon, or when we attempt to comprehend and convey what another, especially a distant culture means by whatever terms they use to denote an activity or product that appears to translate as our 'translation'.

Since we cannot step outside ourselves or do without interpretation, there are no ready solutions to this epistemological paradox. But there may be ways of coming to terms with it. Luhmann's system theory may be one of them, if only because Luhmann is very conscious of the fact that observers cannot at one and the same time observe an object and their own observation of it. But let me look in another direction, one which is closer to the world of translation and which will lead us back to the notion of norms.

It is perhaps in cases where cultural differences are particularly stark that the issues comes to the fore most clearly. That is why we may be able to learn most from a discipline like anthropology. After all, Edmund Leach recognized back in 1973 that for ethnography and anthropology 'the essential problem is one of translation', adding optimistically that 'social anthropologists are engaged in establishing a methodology for the translation of cultural language' (Leach 1973: 772). They found that establishing such a methodology was rather more problematical that they had imagined.

The complexity of the task can be illustrated with reference to a single (abbreviated) example. Early in the twentieth century Christian missionaries who lived for many years among the Nuer of the southern Sudan had concluded that the Nuer possessed a concept of 'religious belief' basically similar to or at least not wholly incompatible with what Westerners would designate as 'religious belief'. It is not unreasonable to think that perhaps the missionaries' assumption of translatability, which assimilated the Nuer conceptual world to their own, also 
facilitated the missionary endeavour itself. The observer's agenda may, consciously or unconsciously, have affected the observation by suggesting self-fulfilling presuppositions. When subsequently the Oxford ethnographer Edward Evans-Pritchard studied the Nuer in the 1940s and ' 50 s, he emphasized the utter otherness of the Nuer concepts and beliefs, their incompatibility with Western, Christian terms. He therefore highlighted the fundamental and formidable problem of understanding and interpreting, let alone of rendering, something which is alien but (presumably, hopefully) approachable through patient 'contextual interpretation', of rendering that in a language like English, i.e. in terms that are familiar to us linguistically and culturally, and therefore in terms that are always already tainted by our concepts, our history, our values. It was Evans-Pritchard who, in a lecture of 1951, described the central task of ethnography as 'the translation of culture' (Needham 1978: 8).

An extended reflection on the linguistic, anthropological and epistemological problems connected with the 'translation of culture' is presented in Rodney Needham's Belief, Language, and Experience (1972), which patiently traces Evans-Pritchard's account of Nuer beliefs. Needham points out, for example, that, if we want to compare the German missionaries' interpretation of the Nuer terms with Evans-Pritchard's, we need to assess what 'adjustments' of Nuer, English and German were required to make the Nuer terms acceptable in the other two languages. When we know from what perspective and with what intention certain Nuer terms were bent or nudged in the direction of the other languages, we get an idea on what basis translation was considered feasible. We could then ascertain the ground on which comparability, commensurability and hence translatability had been constructed. But as Needham (1972: 222) also shows, there is no ideal metalanguage to carry out such a comparison. Such a language could only be constructed on the basis of the comparability of cultural concepts, but the concepts can only be compared on the basis of an already existing ideal metalanguage. That is a vicious circle. We cannot escape from perspectival observation, from value-ridden interpretation, from alwaysalready-compromised translation.

Still, what Evans-Pritchard called 'contextual interpretation' can guard against the danger of rashly, reductively translating another culture's concepts into our terms. I assume Clifford Geertz (1983) had something similar in mind when he stressed the need for the anthropologist's 'participatory' practice as a way of gaining insight from within the culture in question. Speaking in the broader context of the social sciences Craig Calhoun recently argued that social theory should recognize the cultural construction of putatively general categories, pointing out that cross-cultural understanding involves translation problems in the attempt to grasp 'linguistic meanings which are not simply different from our own, but involve incommensurable practices' (1992: 253). He then went on however to argue that translation is perhaps not a good description of cross-cultural understanding, as the latter is a process which must actually change the observer, enabling him or her to play both incompatible cultural games simultaneously without translating the rules and practices of one into those of the other (1992: 256).

While Calhoun's point about the social construction of putatively general categories pinpoints the issue, I must say that I do not see how translation can be avoided in the context of cross-cultural understanding, especially if, in addition to gaining some private understanding, researchers wish to report back on their fieldwork to their own communities. Perhaps we can participate in Nambikwara life until we have become one of them, but only on condition that we resolve to live among the Nambikwara and never return - as indeed Jean de Léry recognized four hundred years ago in the (fictitious) colloquy written 'in the savage language and in French' which he inserted into his (very real) History of a Voyage to the Land of Brazil of 1578 (Léry ed. 
1990, chapter XX; Pagden 1993: 46-47).

If translation, then, cannot be written out of cross-cultural understanding and description, then it matters that translation is governed by, and saturated with, norms and values. And here the somewhat more charged terminology which Eric Cheyfitz employs in his Poetics of Imperialism (1991) proves illuminating. Cheyfitz takes his time to explore the entanglement of translation with metaphor. This is more than just a fortuitous etymological link. Accounts of metaphorical language have traditionally been based on the distinction between the 'normality' of literal, proper, legitimate usage versus the figurative, improper, deviant, illegitimate, foreign, alien, 'abnormal' usage characteristic of metaphor (1991: 88-121). Translation appropriates the foreign, normalizes the abnormal and brands the illegitimate and the improper in the proper words of our own language. Cheyfitz then goes on to consider the translation of the North American Indians into the conceptual system of the early European explorers and settlers - and not only into the Europeans' conceptual, symbolic system, but also, in the same move, into their very material property system. Writing the Indians into a European context, mapping them onto the European world, means re-figuring and translating the other into our schemes. Given the power relations that are involved, it also means imposing our terms and categories. Nowhere is this historically more evident than in the very definition of the other as 'savage', as one who lacks something essential and valuable that we possess and he or she ought also to possess but does not, or possesses in some improper, perverse way which must be put right - whether it be script or scripture, fixed dwellings, certain moral standards or forms of social organization, or indeed clothes or breeches. Faced with the radically different, we construe commensurability by translating on and into our terms. And our terms are not neutral but conditioned. And they cannot be reduced to a matter of equivalence, linguistic or otherwise.

When we engage in historical and cross-cultural studies of translation, we translate other people's concepts and practices of translation on the basis of our own, historical, concept of translation, including its normative aspect and the values it secures. We have no other choice. But having become conscious of the problem inherent in our descriptions we can devise strategies that acknowledge as much. That ought to be part of the ethos of the discipline. In this respect too we can learn from other areas of study. In recent decades ethnographers have become acutely aware of their discipline's roots in colonial history and of its present-day entanglement in structures of power and domination. As a result, ethnography has become markedly more selfreflexive and self-critical, aware of its own historicity and institutional position, of its presuppositions and blind spots, of the pitfalls of representation by means of language and translation. In the study of translation we ignore these issues and debates at our peril. It must be part of the critical practice of our discipline to acknowledge the normativity of our own representations of translation, and thus to make manifest the conditioning of our translation of translation.

\section{REFERENCES}

Arrojo, Rosemary. 1997. 'The 'Death' of the Author and the Limits of the Translator's Invisibility', Translation as Intercultural Communication, ed. Mary Snell-Hornby et al., Amsterdam \& Philadelphia. 21-32.

Baker, Mona. 1998. 'Norms', Routledge Encyclopedia of Translation Studies, ed. Mona Baker, London \& New York. 163-65.

Bakker, Matthijs. 1995. 'Metasprong en wetenschap: een kwestie van discipline,' Vertalen historisch bezien, ed. D. Delabastita \& T. Hermans, 's-Gravenhage. 141-62.

Barthes, Roland. 1977. 'The Death of the Author' [1968] in his Image, Music, Text, trans. Stephen Heath. London. 
Hermans: Translation and Normativity

$142-8$.

Buck, Adrianus de. 1653. Troost-Medecijne-wynckel der zedighe wysheyt ... Door ... Boethius ... Nu vertaelt ... door F.D. Adrianus de Buck. Bruges.

Bourdieu, Pierre. 1994. Raisons pratiques. Sur le théorie de l'action. Paris.

Bourdieu, Pierre. 1996. The Rules of Art. Genesis and Structure of the Literary Field. Trans. Susan Emanuel. Cambridge.

Calhoun, Craig. 1992. 'Culture, History and the Problem of Specificity in Social Theory', Postmodernism and Social Theory, ed. S. Seidman \& D.G. Wagner, Oxford \& Cambridge (Mass.). 244-88.

Cheyfitz, Eric. 1991. The Poetics of Imperialism. Translation and Colonization from The Tempest to Tarzan. New York \& Oxford.

Díaz-Diocaretz, Myriam. 1985. Translating Poetic Discourse. Questions on Feminist Strategies in Adrienne Rich. Amsterdam.

Evans-Pritchard. E.E. 1956 Nuer Religion. New York \& Oxford.

Foucault, Michel. 1979. 'What is an Author', trans. Josué Harari, Textual Strategies. Perspectives in Poststructuralist Criticism, ed. J. Harari. London. 141-60.

Geertz, Clifford. 1983. 'Art as a Cultural System' in his Local Knowledge. Essays in Interpretive Anthropology, London, 1993.

Gorp, H. van, et al. 1997. 'The Study of Literature and Culture: Systems and Fields', special issue, Canadian Review of Comparative Literature 24, 1.

Gouanvic, Jean-Marc. 1997. 'Translation and the Shape of Things to Come', The Translator 3, 2, 125-52.

Harris, Brian. 1990. 'Norms in Interpretation', Target 2, 1, 115-19.

Hermans, Theo. 1996a. (ed.) Door eenen engen hals. Nederlandse beschouwingen over vertalen 155-1670. The Hague.

Hermans, Theo. 1996b. 'Norms and the Determination of Translation: A Theoretical Framework', Translation, Power, Subversion, ed. R. Álvarez \& C.-Á. Vidal, Clevedon. 25-51.

Hermans, Theo. 1997. 'Translation as Institution', in Translation as Intercultural Communication, ed. M. SnellHornby et al., Amsterdam \& Philadelphia, 3-20.

Hermans, Theo. (Forthcoming). 'The Production and Reproduction of Translation. System Theory and Historical Context'. Proceedings of the conference held in Istanbul, October 1996.

Hoven, René. 1997. 'De constantia', Justus Lipsius (1547-1606) en het Plantijnse huis, ed. F. de Nave, Antwerp. $75-$ 81.

Leach, Edmund. 1973. 'Ourselves and Others', The Times Literary Supplement, 6 July 1973, 772.

Lefevere, André. 1992. Translation, Rewriting, and the Manipulation of Literature. London \& New York.

Léry, Jean de. (Ed.) 1990. History of a Voyage to the Land of Brazil [1578], trans. Janet Whatley, Berkeley etc.

Lewis, David.1969. Convention. A Philosophical Study. Cambridge (Mass.).

Littau, Karin. 1993. 'Intertextuality and Translation: The Waste Land in French and German', Translation: the Vital Link, ed. Catriona Picken. London. 63-69

Littau, Karin, 1996. 'Translation in the Age of Postmodern Production: from Text to Intertext to Hypertext', Forum for Modern Language Studies.

Luhmann, Niklas. 1984. Soziale Systeme. Grundriß einer allgemeinen Theorie. Frankfurt. (English translation: Social Systems, trans. John Bednarz Jr., Stanford, 1995).

Luhmann, Niklas. 1986. 'Das Kunstwerk und die Selbstreproduktion der Kunst', Stil. Geschichte und Funktionen eines kulturwissenschaftlichen Diskurselements, ed. H.U. Gumpert \& K.L. Pfeiffer, Frankfurt. 620-72.

Luhmann, Niklas. 1990. 'Weltkunst', in N. Luhmann, F.D. Bunsen and D. Baecker, Unbeobachtbare Welt. Über Kunst und Architektur, Bielefeld. 7-45.

Merton, Thomas. 1973. 'The Normative Structure of Science' [1942] in his The Sociology of Science. Theoretical and Empirical Investigations, ed. Norman W. Storer, Chicago \& London. 267-78.

Needham, Rodney. 1972. Belief, Language, and Experience. Oxford.

Needham, Rodney. 1978. Essential Perplexities. Oxford.

Niranjana, Tejaswini. 1992. Siting Translation. History, Poststructuralism and the Colonial Context. Berkeley.

Pagden, Anthony. 1993. European Encounters with the New World. From Renaissance to Romanticism. New Haven \& London.

Poltermann, Andreas. 1992. 'Normen des literarischen Übersetzens im System der Literatur', Geschichte, System, Literarische Übersetzung / Histories, Systems, Literary Translations, ed. Harald Kittel, Berlin. 5-31.

Pym, Anthony. 1995. 'European Translation Studies, “Une science qui dérange”, and Why Equivalence Needn't be a Dirty Word', TTR, 8, 1, 153-76.

Robinson, Douglas. 1997. What is Translation? Centrifugal Theories, Critical Interventions. Kent/London. 
Simeoni, Daniel. (Forthcoming) 'The Pivotal Status of the Translator's Habitus'. Target.

Skinner, Quentin. 1970. 'Conventions and the Understanding of Speech Acts', The Philosophical Quarterly, 1970, 118-38

Toury, Gideon. 1995. Descriptive Translation Studies and Beyond. Amsterdam \& Philadelphia. 